\title{
The Physical Attributes Most Required in Professional Ballet: A Delphi Study
}

(@)(1) $\odot \ominus$

\author{
Authors

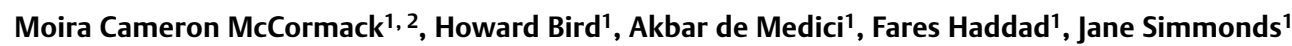

\author{
Affiliations \\ 1 Institute of Sport Exercise and Health, University College \\ London, London, United Kingdom of Great Britain and \\ Northern Ireland \\ 2 The Royal Ballet Company, Healthcare, London, United \\ Kingdom of Great Britain and Northern Ireland
}

\author{
Key words \\ ballet, Delphi, desirable attributes, flexibility, strength
}

$\begin{array}{ll}\text { received } & 27.03 .2018 \\ \text { revised } & 30.09 .2018 \\ \text { accepted } & 02.11 .2018\end{array}$

\section{Bibliography}

DOI https://doi.org/10.1055/a-0798-3570

Online-Publikation: 2018

Sports Med Int Open 2019; 3: E1-E5

(C) Georg Thieme Verlag KG Stuttgart · New York

ISSN 2367-1890

\section{Correspondence}

Ms. Moira Cameron McCormack, MSc

Institute of Sport Exercise and Health Research,

170 Tottenham Court Road

London

W1T 7HA

United Kingdom of Great Britain and Northern Ireland

Tel.: + 44/750/8032 984, Fax: +44/203/4472 800

moira.mccormack@ucl.ac.uk

\begin{abstract}
Background It is commonly accepted that dancers are undoubtedly athletes, with ballet perhaps the most demanding dance form. No previous study has sought to define the physical attributes most desired for classical ballet by professional companies and vocational schools. These are likely to include both aesthetic features and attributes that reduce the risk of injury as well as enhance performance.

Method An initial survey question using the modified Delphi technique was sent using Opinio Survey Software to a selected international expert panel. This was drawn both from those involved in selection of elite professional ballet dancers, and the international medical professionals involved in the care of dancers. The first questionnaire was open-ended to scope for all the physical attributes most favoured by the professional experts.

Results There were 148 responses from the panel of international experts. In total 34 physical attributes were suggested. The 2 most recommended physical criteria for selection into the profession were overall flexibility and overall strength. These results are discussed in the context of the published literature on the mechanics, anatomy and physiology of ballet. Conclusion Flexibility and strength are the 2 features most sought after in elite ballet dancers.
\end{abstract}

\section{Introduction}

Dancers provide a unique blend of athlete and artist [17], for whom ideal physical attributes are just as important as they are in sport. In addition to their performance, musicality, and technique skills, ballet dancers are selected particularly for their physical qualities amongst other attributes [41]. Ballet students are selected into vocational schools based on their potential talent and physical characteristics [41]. However, incidence of injury in professional companies and in vocational schools remains high $[1,11]$. Howse (1970) advocated for physical screening in ballet students at auditions for the Royal Ballet School. This was based on the premise of reducing injury risk [18]. An audition involves participating in a class where a dancer performs for a panel of experts, and because many companies select dancers from their own schools, it can be assumed that professional ballet dancers set the trend for selection into vocational schools. This study was confined to the physical attributes most desired in elite ballet dancers. This study forms the first part of a Delphi Survey designed to provide information on the requirements to identify professional dancers with lower risks of injury than at present. 
Talent identification in aesthetic sports such as gymnastics has been investigated [40] with the conclusion that an appropriate physique in gymnastics for both aesthetic reasons and biomechanical advantages is well known to be important. Such studies have not previously been applied to ballet. Of all dance genres, classical ballet is relatively uniform with a vocabulary that is internationally recognized.

The Delphi technique is a recognised research method that uses a series or round of questionnaires to gather opinions that are continued until a group consensus is achieved $[15,28]$. The technique involves presenting a questionnaire to a panel of preselected, informed individuals or experts to seek their opinion on a particular subject.

In this paper we present and discuss the first round of a Delphi questionnaire in which the physical characteristics most required for classical ballet were obtained, grouped and ranked in order of importance.

\section{Methods}

Ethical approval was obtained from the Ethical Committee of University College London and meets the ethical standards for this journal [16].

\section{Study design}

Purposive sampling was used to identify an initial panel of international professional company directors, vocational ballet school directors, choreographers, senior teachers, principal dancers, exercise specialists, therapists and doctors. This formed a panel of experts involved in the selection, training and therapeutic treatment of dancers. Purposive sampling is a form of non-probability sampling [9]. Depth and specificity of knowledge and expertise were required and therefore a purposive approach was used to recruit appropriate professionals. Snowball sampling was also used to further increase the size of the panel. This method was helpful to access further, well-informed potential participants not known to the researcher [9]. Colleagues in ballet familiar with the criteria for panel inclusion were requested to distribute the questionnaire.

\section{Data collection}

For the first round of the Delphi survey, an anonymous online questionnaire comprising 3 questions was created using Opinio software 7.6.4. Two questions were closed questions, requesting demographic information and profession. The third question was an open-ended question which asked for up to 10 physical attributes expected in today's elite dancer. The request was 'Please list up to 10 physical attributes that you think make a great classical ballet dancer'. Although responses were anonymous it was possible for the researcher to see non-responders in order to send reminders via email.

\section{Data analysis}

Data was downloaded from Opinio to MS Excel. Demographic and profession data was analysed using descriptive statistics. The open question responses were reviewed and inappropriate recommendations were excluded such as psychological or artistic attributes. The remaining data was coded, thematically analysed and grouped into categories of similar responses by the primary researcher. Thematic analysis is useful when assessing the varied responses to an openended question and patterns of similar responses/topics can be grouped allowing the researcher to capture all the data and organise it under distinct headings $[7,19]$. The categories were then reviewed, refined and agreed with 3 members of the research team, $\mathrm{HB}$, JS and AdeM prior to further analysis using descriptive statistics.

\section{Results}

\section{Demographics}

One hundred and forty-eight participants completed and returned questionnaires. The majority of respondents were physiotherapists and ballet teachers ( $\triangleright$ Table 1). Although 6 continents were represented, most of the respondents were from Western Europe and North America ( $>$ Table 2).

\section{Reported physical attributes}

Thirty-four attributes were reported. These are listed in thematic groups ( $>$ Table 3). Overall flexibility, overall strength, turnout, body proportions, and foot and ankle flexibility were the most frequently reported.

\section{Discussion}

This first round of the Delphi Survey highlights the wide-ranging physical attributes preferred in the ballet dancer today. Thirty-four attributes were recommended. A pragmatic approach was then taken to group these into themes to facilitate a synthesized initial discussion prior to the second round of the Delphi.

Overall flexibility was the most frequently recommended attribute by the expert panel. The demands of ballet technique require dancers to have a greater than normal range of movement at the hip

- Table 1 Professional Background of Participants.

\begin{tabular}{|l|l|}
\hline Profession & Number \\
\hline Artistic Director Company & 14 \\
\hline Artistic Director School & 14 \\
\hline Senior Ballet Teacher & 44 \\
\hline Choreographer & 3 \\
\hline Principal Dancer & 8 \\
\hline Exercise Specialist & 10 \\
\hline Physical Therapist & 46 \\
\hline Doctor & 9 \\
\hline
\end{tabular}

- Table 2 Geographical Location of Participants.

\begin{tabular}{|l|l|}
\hline Location & Number \\
\hline Western Europe & 82 \\
\hline North America & 34 \\
\hline Australasia & 18 \\
\hline South America & 7 \\
\hline Eastern Europe & 3 \\
\hline Africa & 2 \\
\hline Asia & 2 \\
\hline
\end{tabular}


- Table 3 Reported Physical Attributes (ranked by frequency of selection and expressed as a percentage), grouped within each of the broad themes most applicable to ballet.

\begin{tabular}{|c|c|c|c|c|}
\hline Theme & & Attribute & Frequency & $\%$ \\
\hline \multirow[t]{9}{*}{ Flexibility } & 1. & Overall flexibility & 86 & 58 \\
\hline & 2. & Hip turnout flexibility & 75 & 50 \\
\hline & 3. & Foot and ankle flexibility & 69 & 46 \\
\hline & 4. & $\begin{array}{l}\text { Good pointe position } \\
\text { (plantarflexion) }\end{array}$ & 21 & 14 \\
\hline & 5. & High extensions & 13 & 8.7 \\
\hline & 6. & Not too hypermobile & 12 & 8 \\
\hline & 7. & Good demi plié (dorsiflexion) & 8 & 5 \\
\hline & 8. & Hyperextended knee & 7 & 4.6 \\
\hline & 9. & Flexible big toe & 2 & 1 \\
\hline \multirow[t]{7}{*}{ Strength } & 10. & Overall strength & 85 & 57 \\
\hline & 11. & Spinal/core strength & 25 & 16.7 \\
\hline & 12. & Foot and ankle strength & 10 & 6.7 \\
\hline & 13. & Power & 12 & 8 \\
\hline & 14. & Ability to jump & 10 & 6.7 \\
\hline & 15. & Leg strength & 4 & 2.6 \\
\hline & 16. & Upper body strength & 1 & 0.6 \\
\hline \multirow[t]{3}{*}{ Coordination } & 17. & Coordination & 34 & 22.8 \\
\hline & 18. & Balance & 13 & 8.7 \\
\hline & 19. & Ability to turn (pirouette) & 1 & 0.6 \\
\hline \multirow[t]{4}{*}{ Stability } & 20. & Overall stability & 3 & 2 \\
\hline & 21. & Spinal stability & 2 & 1 \\
\hline & 22. & Shoulder stability & 2 & 1 \\
\hline & 23. & Control & 36 & 24 \\
\hline \multirow[t]{6}{*}{ Proportions } & 24. & Overall good proportions & 71 & 48 \\
\hline & 25. & Head/neck & 35 & 23 \\
\hline & 26. & Long Legs & 33 & 22 \\
\hline & 27. & Long arms & 17 & 11 \\
\hline & 28. & Short trunk & 14 & 9 \\
\hline & 29. & Height & 2 & 1 \\
\hline \multirow[t]{3}{*}{ Aesthetics } & 30. & Slimness & 45 & 30 \\
\hline & 31. & Leg shape & 17 & 11 \\
\hline & 32. & Beauty & 14 & 9 \\
\hline Fitness & 33. & Stamina & 44 & 29.5 \\
\hline Miscellane-ous & 34. & Eyesight & 1 & 0.6 \\
\hline
\end{tabular}

[6, 14, 26], spine [29], and foot and ankle [34]. The implications of this are reviewed in detail by Day, Koutedakis and Wyon, 2011 [8]. The authors contend that although this is aesthetically attractive, the risks of injury caused by excessive flexibility may have been overlooked, because some $44 \%$ of dancers display hypermobility. However, conventional hypermobility scoring systems are not specifically aimed at dancers and much more research is needed in the area.

Flexibility in dancers is thought to be partly inherited and partly acquired [13]. Inherited characteristics include both the shape of the articulating surfaces of bone and collagen structure $[3,12]$. Additional inherited factors influence range of movement in ballet. External rotation of the hip is further influenced by femoral anteversion angle $[2,30]$, acetabular version and depth, and laxity of the anterior iliofemoral ligament [2]. In addition to these inherited traits, range of movement may also be influenced by prolonged static stretching as part of training [13].

'Hypermobility', normally understood to be a greater than average range of movement at joints compared to the average population [13], was cited as a desirable feature. Inevitably this overlaps with the more frequent selection of 'overall flexibility' as being desirable. The cut point at which flexibility (which more correctly refers to muscle length) becomes 'hypermobility' is somewhat arbitrary even when standard scales not applied to dance are used and many respondents may not have appreciated this. However, because many respondents, in their open comments, specified that desired 'hypermobility' should not be excessive ( $\vee$ Table 3 ), it is probable that the medical community sampled was aware of the greater risk of injury associated with 'hypermobility'.

Referring to the selected physical attributes in $>$ Table 3 , the flexible hip desirable in classical ballet technique is based on 'turnout', where the lower limb is externally rotated and the available range of movement in the hip joint is increased [24]. Turnout is qualified as the summation of external rotation of the lower extremities $[21,24]$ including contributions from the hip, femur, knee, lower-leg, and foot-ankle complex. Sufficient external rotation at the hip in ballet dancers facilitates control of the lower limb and is thought to reduce the risk of injury [2].

Foot and ankle flexibility and good 'pointe' position were often cited as necessary. Ballet dancers weight-bear on extreme ranges of plantar flexion (the en pointe position or $3 / 4$ pointe) $[34,35]$ in order to execute ballet-specific movements and achieve ideal aesthetics. The fully plantar-flexed position must allow the body weight to descend through the tips of the toes encased in the box of the pointe shoe or $3 / 4$ pointe (through the toes and dorsiflexed metatarsophalangeal joints). There is also an important aesthetic element where the plantarflexed foot and ankle continue the length of line of the lower limb. Articulation of the ankle contributes to most of the range of movement, with the remaining contribution from the midfoot [34]. Sufficient weight-bearing dorsiflexion is required to allow the dancer to execute the 'demi plié', which allows dancers to execute explosive jumps as well as sustained manoeuvres $[5,20]$. Range of motion here relies on bone shape, soft tissue laxity and neuromuscular tone.

Strength was also frequently reported. The leaps and jumps in ballet demand high muscle torque as well as the balance and postural control required for highly complex moves such as pirouettes. In the past dancers have been considered not as fit or well conditioned as equivalent athletes [23] particularly with respect to strength. However, there has been a movement over the last 5 years to include strength training in dancers' conditioning [22]. Dowse et al. (2017) advocate for resistance training in dancers, because in their study dynamic balance, lower-body strength and power were improved without affecting artistic or aesthetic components [10].

Core strength and spinal stability, referred to in $>$ Table 3, often come under the term core stability, which is the integration of passive (non-contractile), active (contractile), and neural structures to minimize the effects of external forces and maintain stability [31]. However, this is really a default term applied to all motor control training around the trunk. Core strength, motor control stability and endurance involve different concepts [27]. Injuries to the lower back are high in professional and pre-professional dance 
$[1,11]$ and lack of pelvic stability has been implicated [33]. Impaired core proprioception has also been shown to be predictive of knee injury in female athletes [42]. Further examination of all the components of core stability - core power, strength, endurance and sensory-motor control - is advised in order to understand its multifactorial role in reducing injury and enhancing performance in dancers [31].

Stamina is another attribute important in the elite dancer. This was reported by nearly one-third of respondents. Classical ballet is characterized as a high-intensity, intermittent form of exercise $[32,38]$ demanding muscle power reserves for explosive jumps, muscular endurance to maintain high levels of power output, and cardiorespiratory endurance to execute low-intensity exercise. Without these physiological foundations, the dancer is left susceptible to fatigue, and this in turn has an effect on skill and alignment which may increase the risk of injury [38]. Therefore it is believed that enhancing these foundations also enhances aesthetic competence [32] and artistry, and frees the dancer to perform to music, express emotion, and thus captivate an audience.

Motor control and coordination requires an integration of visual, vestibular, and somatosensory information to facilitate accurate positioning and movement of the body in space [36]. Dance training requires the integrity of sensory inputs to coordinate the musculature of the body and to maintain proper alignment while moving through the positions and shapes intrinsic to it [36, 37].

Physical proportions scored highly in the survey with almost half of the panel highly ranking good proportions. Ballet is demanding in all the above physiological, anatomical, and functional characteristics but remains an art form, and aesthetic attributes are also important. So far, the literature has identified the ideal balletic physique as primarily ectomorphic $[25,39]$. The Vaganova School in St. Petersburg measures and compares lower limb length to trunk length at audition for vocational training in order to attain physical conformity (G. Anthony, personal communication, July 17, 2016). Head and neck proportions as well as slimness are preferred in professional ballet. The slim physique in ballet has been much criticised [4], but lightness and an ability to show "line" in balletic positions are the aesthetic required.

Inevitably there are some weaknesses in this preliminary study. The artistic directors ( $18 \%$ of participants) of companies and schools make the final decisions in recruitment to the profession, but they are supported by their artistic staff of senior ballet teachers ( $29.7 \%$ of the survey panel), who still have a significant influence. Inevitably there will be more teachers than artistic directors. The physiotherapists, doctors and health professionals who participated were all selected because of proven involvement in dance, usually evidenced by their research in dance. Physiotherapists are used in many institutions to screen candidates in support of panel decisions. Their inclusion adds the perspective of injury prevention to the study, and a more detailed future analysis of how the responses of the participating groups differed is planned.

Neither were sex-specific physical attributes studied, although this also could form the basis of an interesting and important future study.

We believe this investigation is the first of its kind to obtain the preferences from those international experts in the profession who select dancers as well as those who care for dancers' health. It is clear that generalized flexibility takes precedence though specific examples such as hip turnout and foot and ankle flexibility are also sought. However, flexibility can never be separated from strength and control in achieving the range of controlled movement required. Aesthetic requirements were also considered but ranked as less important.

These results will form the basis for further rounds of the Delphi Survey in order to arrive at a consensus. It is hoped this might help guide those who train and those who care for dancers both in performance enhancement and injury risk management.

\section{Acknowledgements}

Private Physiotherapy Education Foundation Rudolf Nureyev Foundation Harlequin Floors UK.

\section{Conflict of Interest}

The authors declare that they have no conflict of interest.

\section{References}

[1] Allen N, Nevill A, Brooks ], Koutedakis Y, Wyon M. Ballet Injuries: Injury incidence and severity over 1 year. J Orthop Sports Phys Ther 2012; 42: 781-790

[2] Bauman P, Singson R, Hamilton W. Femoral neck anteversion in ballerinas. Clin Orthop Relat Res 1993; 302: 57-63

[3] Beighton P, Grahame R, Bird H. Hypermobility of Joints. London: Springer-Verlag; 2011: 11

[4] Benn T, Walters D. Between Scylla and Charybdis. Nutritional education versus body culture and the ballet aesthetic: The effects on the lives of female dancers. Res Dance Educ 2010; 2: 139-154

[5] Bennell K, Khan KM, Matthews B, De Gruyter M, Cook E, Holzer K, Wark DJ. Hip and ankle range of motion and hip muscle strength in young novice female ballet dancers and controls. Br J Sports Med 1999; 33: 340-349

[6] Champion LM, Chatfield SJ. Measurement of turnout in dance research. J Dance Med Sci 2008; 12: 121-135

[7] Cohen L, Manion L, Morrison K. Research Methods in Education. $6^{\text {th }}$ ed. London: Routledge Falmer; 2007

[8] Day H, Koutedakis Y, Wyon MA. Hypermobility and dance: A review. Int J Sports Med 2011; 32: 485-489

[9] Day J, Bobeva M. A generic toolkit for the successful management of Delphi studies. EJBRM 2005; 3: 103-116

[10] Dowse R.The effects of a training intervention on strength, power and performance in adolescent dancers [Thesis], Auckland, New Zealand: Auckland University of Technology; 2015. Retrieved from Google Scholar aut.researchgateway.ac.nz

[11] Ekengren CL, Quested R, Brodrick A. Injuries of pre-professional ballet dancers: Incidence, characteristics and consequences. J Sci Med Sport 2014; 17: 271-275

[12] Foley F, Bird H. Hypermobility in dance: Asset, not liability. Clin Rheumatol 2013; 32: 455-461

[13] Gannon LM, Bird HA. The quantification of joint laxity in dancers and gymnasts. J Sports Sci 1999; 17: 743-750

[14] Hamilton WG, Hamilton LA, Marshall P, Molnar M. A profile of the musculoskeletal characteristics of elite professional ballet dancers. Am J Sports Med 1992; 20: 267-273 
[15] Hardy D], O'Brien AP, Gaskin C], O’Brien A], Morrison-Ngatai E, Skews G, Ryan T, McNulty N. Practical application of the Delphi technique in a bicultural mental health nursing study in New Zealand. J Adv Nurs 2004; 46: 95-109

[16] Hariss DJ, Macsween A, Atkinson G. Standards for ethics in sport and exercise research: 2018 update. Int J Sports Med 2017; 38: 1126-1131

[17] Hincapié CA, Morton EJ, Cassidy DJ. Musculoskeletal injuries and pain in dancers: A systematic review. Arch Phys Med Rehabil 2008; 89: 1819-1829

[18] Howse J, McCormack M. Dance Technique and Injury Prevention. London: A\&C Black; 2009: 96

[19] Joffe H. Thematic analysis. In: Harper D, Thompson AR. (eds.) Qualitative Research Methods in Mental Health and Psychotherapy: A Guide for Students and Practitioners. London: John Wiley \& Son; 2011: 210-223

[20] Kadel N], Donaldson-Fletcher BA, Gerberg LF, Michel LJ. Anthropometric measurements of young ballet dancers. J Dance Med Sci 2005; 9: 84-90

[21] Kahn K, Roberts P, Nattrass C, Bennell K, Mayes S, Way S, Brown ], McMeekan J, Wark J. Hip and ankle range of motion in elite classical ballet dancers and controls. Clin J Sport Med 1997; 7: 174-179

[22] Kolokythas N. Strength training for female dancers. One 2017; 2: 10-12

[23] Koutedakis $\mathrm{Y}$, Jamurtas $\mathrm{A}$. The dancer as a performing athlete. Sports Med 2004; 34: 651-661

[24] Kushner S, Saboe L, Reid D, Penrose T, Grace M. Relationship of turnout to hip abduction in professional dancers. Am J Sports Med 1990; 18: 286-291

[25] Liiv H, Wyon MA, Jürimäi T, Saar M, Mäestu J, Jürimäe J. Anthropometry, somatotypes, and aerobic power in ballet, contemporary dance, and dancesport. Med Probl Perform Art 2013; 12: 205-211

[26] Lowrie M, Chatfield S]. Measurement of turnout in dance research. J Dance. Med Sci 2008; 12: 121-135

[27] McNeill W. Core stability is a subset of motor control. J Bodyw Mov Ther 2010; 14: 80-83

[28] Mead D, Moseley L. The use of the Delphi as a research approach. Nurs Res 2001; 8: 4-23
[29] Nilsson C, Wykman A, Leanderson J. Spinal sagittal mobility and joint laxity in young dancers. Knee Surg Sports Traumatol Arthrosc 1993; 1 : 206-208

[30] Quanbeck AE, Russell JA, Handley SC, Quanbeck DS. Kinematic analysis of hip and knee rotation and other contributors to ballet turnout. J Sports Sci 2017; 35: 331-338

[31] Rickman AM, Ambegaonkar JP, Cortes N. Core stability: Implications for Dance Injuries. Med Probl Perform Art 2012; 27: 159-164

[32] Rodrigues-Kraus ], Krause M, Reischak-Oliveira A. Cardiorespiratory considerations in dance. J Dance Med Sci 2015; 19: 91-102

[33] Roussel NA, Nijs J, Mottram S, Van Moorsel A, Truijen S, Stassijns G. Altered lumbopelvic movement control but not generalized joint hypermobility is associated with increased injury in dancers. A prospective study. Man Ther 2009; 14: 630-635

[34] Russell JA, Shave RM, Kruse DW, Koutedakis Y, Wyon MA. Ankle and foot contributions to extreme plantar- and dorsiflexion in female ballet dancers. Foot Ankle Int 2011; 32: 183-188

[35] Russell JA. Preventing dance injuries: Current perspectives. Open Access J Sports Med 2013; 4: 199-210

[36] Schmit JM, Regis DI, Riley MA. Dynamic patterns of postural sway in ballet dancers and track athletes. Exp Brain Res 2005; 163: 370-378

[37] Simmons RW. Sensory organization determinants of postural stability in trained ballet dancers. Int J Neurosci 2009; 115: 87-97

[38] Twitchett EA, Koutedakis Y, Wyon MA. Physiological fitness and professional classical ballet performance:a brief review. J Streng Cond Res 2009; 23: 2732-2740

[39] Twitchett EA, Angioi M, Metsios G, Koutedakis Y, Wyon MA. Body composition and ballet injuries. Med Probl Perform Art 2008; 9: 93-98

[40] Vandorpe B, Vandendriessche J, Vaeyens R, Pion J, Philippaerts R, Lenoir $\mathrm{M}$. Factors discriminating gymnasts by competitive level. Int J Sports Med 2011; 32: 591-597

[41] Walker IJ, Nordin-Bates SM, Redding E. Talent identification and development in dance: A review of the literature. Res Dance Educ 2010; 11: 167-191

[42] Zazulac BT, Hewett TE, Reeves NP, Goldberg B, Cholewicki J. The effects of core proprioception on knee injury: A prospective biomechanical-epidemiological study. Am J Sports Med 2007; 35 368-373 